Proc. Estonian Acad. Sci. Eng., 2004, 10, 1, 53-62

\title{
Correction of the short-term forecast of high-voltage power consumption
}

\author{
Taivo Kangilaski and Vladimir Jaanimägi \\ Eesti Energia AS, Laki 24, 12915 Tallinn, Estonia; Taivo.Kangilaski@energia.ee \\ Received 18 December 2002, in revised form 11 July 2003
}

\begin{abstract}
This paper describes and proves an algorithm for approximating the high-voltage power forecasted consumption with a model function. The first and second derivatives are used to describe the real consumption function. The algorithm is used in Eesti Energia AS for the analysis and technical management of large-scale transmission networks.
\end{abstract}

Key words: short-term forecast, high-voltage power consumption, function approximation.

\section{INTRODUCTION}

In order to calculate power consumption regimes for the time ahead, one needs consumption forecasts for that time. As a result, the system operators face short-term forecasting problems, involving the loads during the next hour, the next day, and the next week $\left.{ }^{1}\right]$. In our experiments, forecasting short-term consumption for high-voltage power consumption, the feed-forward neural networks (FNN) are used [,3].

Our goal was to develop an algorithm for short-term forecasts that would give the consumption data per hour for eight days with the required accuracy. The generated consumption forecast is usable at the national dispatch center.

For the consumption forecast on the day $x$ for the day $x+1$, data up to the day $x-1$ is available. For the first four days, an error of $\pm 3 \%$ suggests an accurate forecast, and for the last four days an error of $\pm 6 \%$ indicates a high accuracy.

Separate neural networks were developed for all the hours of the 8 days. To establish the input data for a short-time forecast of power consumption, a day was divided into four 6-hour periods. Every hour was described by the statistical consumption data, temperature, light intensity, the number of the day (1-7) in the week, and the number of the month. As for the temperature only minimum and 
maximum temperature of a forecasted day was used, because other information was not available. However, such an information is not sufficient to forecast the consumption curve, because the functional relation between temperature and consumption is missing. To create a functional relation, the temperature for each hour is created through its minimum and maximum values. Unfortunately, it means that FNNs of successive hours converge almost independently to the local minimum $\left.{ }^{2,4-6}\right]$. In reality, the hourly consumptions are related because consumption has inertia.

Thus the real consumption function was not established (not sufficiently smooth and may occasionally be illogically non-monotonic) because all hourly data of consumption are forecasted autonomously.

There are two possibilities to improve the consumption forecast, either by using the temperature or the consumption. Because we have insufficient information about the temperature of a forecasted day, consumption was chosen. By using consumption it is possible, for instance, to forecast the average consumption of a forecasted day and then add this value to the hourly FNN. By adding a new input to the FNN, the learning speed will be retarded because of the voluminous FNN calculus $\left[^{2,5,7}\right]$. In order to solve this problem, when the data from the FNN is within the required accuracy but do not satisfy the curve of consumption (sometimes FNN output does not have a derivative), we have to create a logic that would enable us to approximate the FNN data with a function. The approximation result should guarantee that all approximated hours remain in the permitted bounds around the real consumption (Fig. 1.).

The proposed methodology is less voluminous than adding a new input to the FNN. Thus, we are faced with the problem of construction of a model of the consumption curve.

By the conventional approach $\left[{ }^{8}\right]$ to solving an approximation problem, it is presumed that the real function is known. It means that actual values of the function at specific points are known. The other presumption is that it is possible

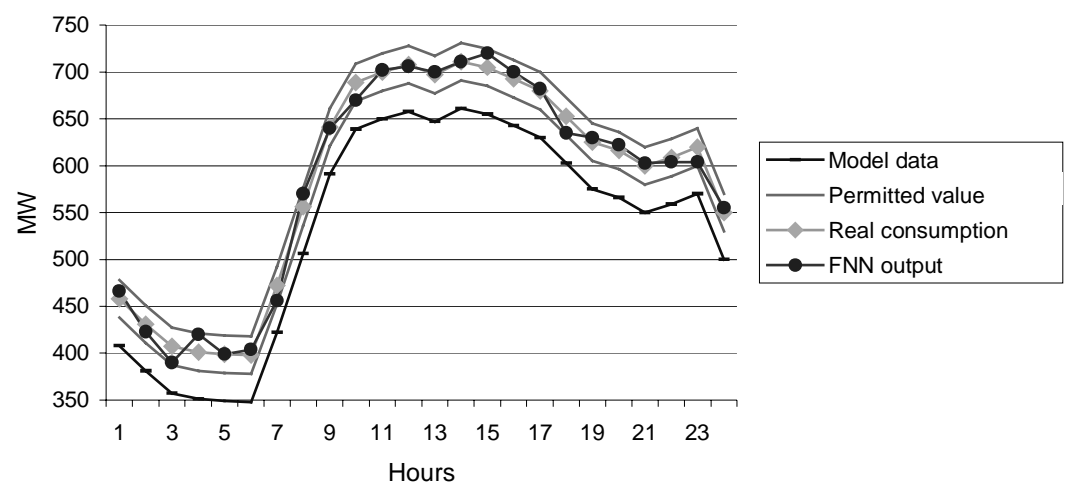

Fig. 1. The curves for approximate short-time consumption forecast. 
to construct a set of sub-functions which converge to the real function. The speed of convergence (in Chebyshev meaning) is investigated with the least squares method. Thus, in the conventional theory of approximation, the convergence of functions is established through the following steps. Firstly, a set of functions is selected. For that many different possibilities exist, such as the trigonometrical polynomial approach, algebraic approach, splines, linear functions, etc. $\left.{ }^{5,8,9}\right]$. Secondly, the converging series of functions and its limit are determined. Finally, based on the conventional model of approximation the function is smoothed.

In our case, the presumptions of the conventional approach were not satisfied. The curve of forecasted consumption, created with the FNN, was different from the real one. In addition, the values of the specific points were not known. To solve the problem, it was necessary to find a function, the derivatives of which are close to those of the model function. In our case the values of the sub-functions are known only at specific points (in our case the hours of a day). However, these functions are not differentiable. Therefore we developed the principles for creating series of differentiable functions. For that purpose, convergence of the series of such functions to the required marginal value was proved.

An algorithm for smoothing a selected function was developed, with a continuous check of whether the on-going basis of that approximation is within the specified limits of accuracy.

\section{INITIAL DATA}

To construct a model of the consumption curve, the consumption data were analysed. We presumed that the consumption curve may be divided into four groups, inside of which the consumption is similar.

Group 1: hours between 1 to 8 on Tuesdays, Wednesdays, Thursdays, and Fridays.

Group 2: hours between 1 to 8 on Saturdays, Sundays, Mondays, and public holidays.

Group 3: hours between 9 to 24 on Mondays, Tuesdays, Wednesdays, Thursdays, and Fridays.

Group 4: hours between 9 to 24 on Saturdays and Sundays.

Using the rules, described in Chapter 1, the model of the consumption function $f_{E}(t)$ was created.

The approximation engine uses the following functions as input data:

1) an arbitrary twice differentiable $\left(\mathrm{C}^{2}\right)$ function $f(t)$,

2) a function of forecasted consumption $f_{F}(t)$, created through the FNN,

$3)$ the model of the consumption function $f_{E}(t)$.

Argument $t$ indicates an hour of a day: $t \in[a, b]$. For the algorithm it is presumed firstly, that

$$
f(t), f_{F}(t), f_{E}(t) \in \mathrm{C}^{2},
$$


and, secondly, functions $f_{F}^{\prime}(t)$ and $f_{E}^{\prime}(t)$ are equally bounded:

$$
\left|f_{F}^{\prime}(t)\right| \leq B, \quad\left|f_{E}^{\prime}(t)\right| \leq B
$$

where $B$ is a positive constant. In fact, the condition (2) is not a restriction, because the high-voltage power consumption changes smoothly. The variables $[a, b]$ are selected from the interval of $[0,23]$. In addition, a presumption was made that all the functions have an infinite amount of positive values in the interval $[a, b]$ :

$$
f:[a, b] \rightarrow[0,+\infty), \quad f_{F}:[a, b] \rightarrow[0,+\infty), \quad f_{E}:[a, b] \rightarrow[0,+\infty),
$$

and all these functions satisfy the condition

$$
f(t), f_{F}(t), f_{E}(t) \in L,
$$

where $L$ is a set of functions that satisfy the Lipschitz condition $\left[{ }^{10}\right]$. The Lipschitz condition holds, for example, for a monotone, continuous, and bounded function

$$
\left|f\left(t_{k}\right)-f\left(t_{k+1}\right) \| \leq D\right| t_{k}-t_{k+1} \mid,
$$

where $D$ is a positive constant and $t_{k}, t_{k+1} \in[a, b]$. It is obvious that $L \supset \mathrm{C}^{2}$.

The goal is to find an approximated consumption curve $f_{R}(t), t \in[a, b]$ by applying the function $f_{E}(t)$ to the function $f_{F}(t)$ in such a way that the following condition holds:

$$
\left|f_{R}^{\prime}(t)-f_{E}^{\prime}(t)\right|=\min _{f \in\left\{\max _{t \in[a, b]}\left|f(t)-f_{F}(t)\right|\right\}<\varepsilon}\left|f^{\prime}(t)-f_{E}^{\prime}(t)\right|,
$$

where $\varepsilon$ is a positive constant that determines the required precision.

\section{SOLUTION}

To solve the defined problem, to find $f_{R}(t)$, we can divide the interval $[a, b]$ into $m+1$ segments ( $m$ is a sufficiently large positive constant) as follows:

$$
\begin{array}{ll}
{\left[t_{0}, t_{1}\right]:} & \left|f_{F}(0)-f_{F}(t)\right|<\varepsilon / B ; t \in\left[t_{0}, t_{1}\right] ; t_{1}-t_{0}<\varepsilon /(3 B), \\
{\left[t_{1}, t_{2}\right]:} & \left|f_{F}\left(t_{1}\right)-f_{F}(t)\right|<\varepsilon / B ; t \in\left[t_{1}, t_{2}\right] ; t_{2}-t_{1}<\varepsilon /(3 B), \\
{\left[t_{2}, t_{3}\right]:} & \left|f_{F}\left(t_{2}\right)-f_{F}(t)\right|<\varepsilon / B ; t \in\left[t_{2}, t_{3}\right] ; t_{3}-t_{2}<\varepsilon /(3 B), \\
\ldots \ldots & \\
{\left[t_{m}, t_{m+1}\right]:} & \left|f_{F}\left(t_{n}\right)-f_{F}(t)\right|<\varepsilon / B ; t \in\left[t_{m}, t_{m+1}\right] ; t_{m+1}-t_{m}<\varepsilon /(3 B),
\end{array}
$$




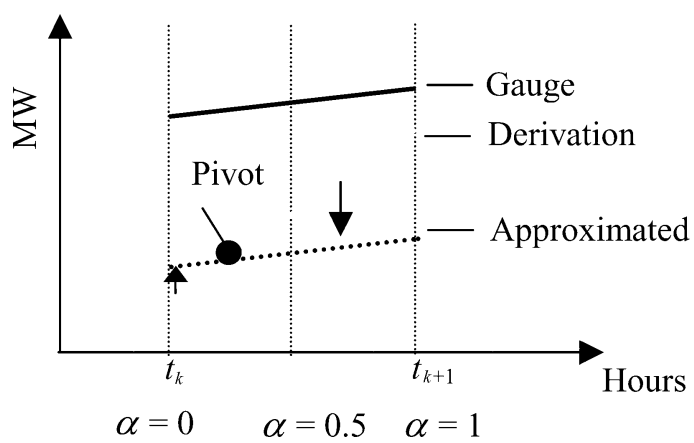

Fig. 2. Usage of the derivative pivot.

where $t_{0}=a$ and $t_{m+1}=b$. That kind of division is possible because initial functions are continuous.

Let us now construct a series of functions $\left\{\bar{f}_{n}(t)\right\}_{n=1}^{\infty}$, where $t \in[a, b]$ and the index $n$ indicates the range number of the function in the series. The values of the functions in the series at points $\left\{t_{0}, t_{1}, t_{2}, \ldots, t_{m+1}\right\}$ were investigated. The elements of the series were constructed as follows:

$$
\begin{gathered}
\bar{f}_{1}:\left\{\begin{array}{l}
\bar{f}_{1}\left(t_{k}\right)=f_{1}\left(t_{k}\right), \\
\bar{f}_{1}\left(t_{k+1}\right)=f_{1}\left(t_{k+1}\right), \\
\ldots
\end{array}\right. \\
\bar{f}_{n+1}:\left\{\begin{array}{l}
\bar{f}_{n+1}\left(t_{k}\right)=\bar{f}_{n}\left(t_{k}\right)-\left[f_{2}^{\prime}\left(t_{k}\right)-\bar{f}_{n}\left(t_{k}\right)\right] \cdot \alpha\left(t_{k+1}-t_{k}\right), \\
\bar{f}_{n+1}\left(t_{k+1}\right)=\bar{f}_{n}\left(t_{k+1}\right)+\left[f_{2}^{\prime}\left(t_{k}\right)-\bar{f}_{n}\left(t_{k}\right)\right] \cdot(1-\alpha)\left(t_{k+1}-t_{k}\right),
\end{array}\right. \\
k=0,1, \ldots, m .
\end{gathered}
$$

An important element in Eq. (8) is the constant $\alpha, \alpha \in[0,1]$, that specifies a derivative pivot in the interval (Fig. 2). The derivative will be conjugated as long as it is parallel with the segment of the model function.

The hypothesis is that the constructed series of functions $\left\{\bar{f}_{n}(t)\right\}_{n=1}^{\infty}$ converges to the desired approximated consumption function $f_{R}(t), t \in[a, b]$. All shortterm consumption forecastings in ENav are based on this hypothesis.

\section{THEOREMS AND PROOFS}

To prove the convergence of the series of the functions to the desired function $f_{R}(t), t \in[a, b]$, based on the common mathematical principles $\left[{ }^{11}\right]$, we have to prove its convergence, and find the convergence speed and its marginal value that satisfies the condition (6). 
Theorem 1. A series of functions $\left\{\bar{f}_{n}(t)\right\}_{n=1}^{\infty}$ converges to $f_{R}(t)$, where $t \in[a, b]$.

Proof. It is known that a series of functions converges when all sub-series of the series converge. In our context, it is not a necessary condition for the algorithm. In the context of our algorithm, we consider the series of functions as converging when one of the sub-series of the series converges to $f_{R}(t)$. To prove that $\lim _{n \rightarrow \infty}\left\{\bar{f}_{n}(t)\right\}=$ $f_{R}(t)$, we have to prove two additional propositions: first, $\left|\hat{f}_{n}(t)-f_{F}(t)\right|<\varepsilon$, where $n=1, \ldots, \infty$ and $t \in[a, b]$; second, we need to prove that the series $\left\{\bar{f}_{n}(t)\right\}_{n=1}^{\infty}$ has a marginal value $\left[{ }^{11}\right]$.

Proposition 1.1. $\left|\bar{f}_{n}(t)-f_{F}(t)\right|<\varepsilon / 3$, where $n=1, \ldots, \infty$ and $t \in[a, b]$.

Proof. If $n=1$, then proposition 1.1 is true because of definition (7). Let us assume that proposition 1.1 is true if $n=n_{0}$. Let us now prove that proposition 1.1 is true if $n=n_{0}+1$. Here we will use the method of mathematical induction:

$$
\begin{gathered}
\left|\bar{f}_{n_{0}+1}\left(t_{k}\right)-f_{F}\left(t_{k}\right)\right|=\left|\bar{f}_{n_{0}}\left(t_{k}\right)-\left[f_{E}^{\prime}\left(t_{k}\right)-\bar{f}_{n}\left(t_{k}\right)\right] \cdot \alpha\left(t_{k+1}-t_{k}\right)-f_{F}\left(t_{k}\right)\right|, \\
\left|\bar{f}_{n_{0}+1}\left(t_{k}\right)-f_{F}\left(t_{k}\right)\right| \leq\left|\bar{f}_{n_{0}}\left(t_{k}\right)-f_{F}\left(t_{k}\right)\right|+\alpha\left(t_{k+1}-t_{k}\right)\left|f_{E}^{\prime}\left(t_{k}\right)-\bar{f}_{n}\left(t_{k}\right)\right| \leq \varepsilon .
\end{gathered}
$$

As we see from Eq. (10), $\left|\bar{f}_{n_{0}}\left(t_{k}\right)-f_{F}\left(t_{k}\right)\right|<\varepsilon / 3$ and because the functions $f_{E}^{\prime}\left(t_{k}\right)$ and $\bar{f}_{n}\left(t_{k}\right)$ in the second member in (9) satisfy the Lipschitz condition, their derivatives are bounded. It means that the second member of Eq. (10) can be divided into infinitely small segments of decreasing length.

Using the same logic, we can prove for $t_{k+1}$ that $\left|\bar{f}_{n}\left(t_{k+1}\right)-f_{F}\left(t_{k+1}\right)\right|<\varepsilon$. It means that the proposition 1.1 is true for $n=n_{0}+1$.

Let us consider the case $t \in\left[t_{k}, t_{k+1}\right]$. In that case

$$
\begin{aligned}
\left|\bar{f}_{n}(t)-f_{F}(t)\right| & \leq\left|\bar{f}_{n}(t)-\bar{f}_{n}\left(t_{k}\right)\right|+\left|\bar{f}_{n}\left(t_{k}\right)-f_{F}\left(t_{k}\right)\right|+\left|f_{F}\left(t_{k}\right)-f_{F}(t)\right| \\
& \leq B\left(t_{k+1}-t_{k}\right)+\varepsilon / 3+\varepsilon / 3 .
\end{aligned}
$$

Since $\left(t_{k+1}-t_{k}\right)$ is infinitely small, we may rewrite Eq. (11) as follows:

$$
B\left(t_{k+1}-t_{k}\right)+\varepsilon / 3+\varepsilon / 3 \leq B \frac{\varepsilon}{3 B}+\frac{\varepsilon}{3}+\frac{\varepsilon}{3}=\varepsilon .
$$

Thus proposition 1.1 is proved.

Proposition 1.2. Series $\left\{\bar{f}_{n}(t)\right\}_{n=1}^{\infty}$ has a marginal value.

Proof. In this case we face a problem of proving the convergence. Let us define $A$ as

$$
A=\max _{t \in[a, b]}\left|f_{F}(t)\right| .
$$


We may define $A$ in this way, because $f_{F}(t)$ is continuous and each continuous function that is specified in a finite set is bounded:

$$
\left|\bar{f}_{n}(t)\right|=\left|\bar{f}_{n}(t)-f_{F}(t)+f_{F}(t)\right|<\left|\bar{f}_{n}(t)-f_{F}(t)\right|+\left|f_{F}(t)\right| \leq \frac{B}{3} \varepsilon+A .
$$

The series $\left\{\bar{f}_{n}(t)\right\}_{n=1}^{\infty}, t \in[a, b]$ is bounded; it means that there exists a subseries $\left\{\bar{f}_{n_{i}}(t)\right\}^{\infty}$ that converges to a certain function (from the Weierstrass theorem $\left.\left[{ }^{11}, 12\right]\right)_{i}$. Let us presume that this is our desired approximated consumption function $f_{R}(t)$. Thus, Proposition 1.2 and Theorem 1 are proved.

Theorem 2. The marginal value of the series of functions $\left\{\bar{f}_{n}(t)\right\}_{n=1}^{\infty}$ satisfies the condition

$$
\left|f_{R}^{\prime}(t)-f_{E}^{\prime}(t)\right|=\min _{f \in\left\{\max _{t \in[a, b]}\left|f(t)-f_{F}(t)\right|\right\}<\varepsilon}\left|f^{\prime}(t)-f_{E}^{\prime}(t)\right| .
$$

Proof. To estimate the marginal value of the series $\left\{\bar{f}_{n}(t)\right\}_{n=1}^{\infty}$, let us estimate the derivatives of the element $n+1$ :

$$
\left(\bar{f}_{n+1}\left(t_{k+1}\right)-\bar{f}_{n+1}\left(t_{k}\right)\right)=\left(\bar{f}_{n}\left(t_{k+1}\right)-\bar{f}_{n}\left(t_{k}\right)\right)+\left(f_{E}^{\prime}\left(t_{k}\right)-\bar{f}_{n}^{\prime}\left(t_{k}\right)\right)\left(t_{k+1}-t_{k}\right) .
$$

We have

$$
\frac{\bar{f}_{n+1}\left(t_{k+1}\right)-\bar{f}_{n+1}\left(t_{k}\right)}{t_{k+1}-t_{k}}=\frac{\bar{f}_{n+1}\left(t_{k+1}\right)-\bar{f}_{n}\left(t_{k}\right)}{t_{k+1}-t_{k}}+f_{E}^{\prime}\left(t_{k}\right)-\bar{f}_{n}^{\prime}\left(t_{k}\right) .
$$

When $t_{k+1}-t_{k}$ is small enough, it expresses a derivative

$$
\frac{\bar{f}_{n+1}\left(t_{k+1}\right)-\bar{f}_{n}\left(t_{k}\right)}{t_{k+1}-t_{k}} \approx f_{n}^{\prime}\left(t_{k}\right) \text {. }
$$

From Eq. (17) we can conclude that

$$
\frac{\bar{f}_{n+1}\left(t_{k+1}\right)-\bar{f}_{n+1}\left(t_{k}\right)}{t_{k+1}-t_{k}}
$$

converges to $f_{E}^{\prime}\left(t_{k}\right)$.

From Proposition 1.1 we find that the same formula will converge also to $f_{R}^{\prime}\left(t_{k}\right)$. It means that

$$
f_{R}^{\prime}\left(t_{k}\right) \approx f_{E}^{\prime}\left(t_{k}\right)
$$

Thus from Eq. (6) we can see that Theorem 2 is proved. 
Theorem 3. $\left|\bar{f}_{n}(t)-f_{R}(t)\right|<S \cdot \frac{1}{n \sqrt{n}}$, if $n \rightarrow \infty$. It means that these two functions have the same convergence speed ( $n$ indicates the range number of the function in the series).

Proof. Let us estimate the convergence speed at the end points of the segment $\left[t_{k}, t_{k+1}\right]$, where $k=0,1, \ldots, m+1$. We will use Eq. (6) for a segment end point $t_{k+1}:$

$$
\begin{aligned}
\bar{f}_{n+1}\left(t_{k+1}\right)=\bar{f}_{n}\left(t_{k+1}\right)+\left(f_{E}^{\prime}\left(t_{k+1}\right)-\bar{f}_{n}^{\prime}\left(t_{k+1}\right)\right) \alpha\left(t_{k+1}-t_{k}\right) \\
\quad=\bar{f}_{n-1}\left(t_{k+1}\right)+\left(f_{E}^{\prime}\left(t_{k+1}\right)-\bar{f}_{n-1}^{\prime}\left(t_{k+1}\right)\right) \alpha\left(t_{k+1}-t_{k}\right)+\left(f_{E}^{\prime}\left(t_{k+1}\right)-\bar{f}_{n}^{\prime}\left(t_{k+1}\right)\right) \alpha\left(t_{k+1}-t_{k}\right) \\
=\bar{f}_{n-1}\left(t_{k+1}\right)+\alpha\left(t_{k+1}-t_{k}\right)\left[2 f_{E}^{\prime}\left(t_{k+1}\right)-\sum_{i=0}^{1} \bar{f}_{n-i}^{\prime}\left(t_{k+1}\right)\right] \\
=\bar{f}_{n-2}\left(t_{k+1}\right)+\alpha\left(t_{k+1}-t_{k}\right)\left[3 f_{E}^{\prime}\left(t_{k+1}\right)-\sum_{i=0}^{2} \bar{f}_{n-i}^{\prime}\left(t_{k+1}\right)\right] \\
=\ldots \ldots \\
=\bar{f}_{1}\left(t_{k+1}\right)+\alpha\left(t_{k+1}-t_{k}\right)\left[n f_{E}^{\prime}\left(t_{k+1}\right)-\sum_{i=0}^{n-1} \bar{f}_{n-i}^{\prime}\left(t_{k+1}\right)\right] \\
=\bar{f}_{1}\left(t_{k+1}\right)+\alpha\left(t_{k+1}-t_{k}\right)\left[n f_{E}^{\prime}\left(t_{k+1}\right)-\sum_{i=1}^{n} \bar{f}_{i}^{\prime}\left(t_{k+1}\right)\right]
\end{aligned}
$$

The left side of the basic formula of Theorem 3 can be written as

$$
\begin{aligned}
& \left|\bar{f}_{n}\left(t_{k+1}\right)-f_{R}\left(t_{k+1}\right)\right| \\
& \quad=\left|\bar{f}_{1}\left(t_{k+1}\right)+\alpha\left(t_{k+1}-t_{k}\right)\left[n f_{E}^{\prime}\left(t_{k+1}\right)-\sum_{i=1}^{n} \bar{f}_{i}^{\prime}\left(t_{k+1}\right)\right]-f_{R}\left(t_{k+1}\right)\right| \\
& \quad \leq\left|\bar{f}_{1}\left(t_{k+1}\right)-f_{R}\left(t_{k+1}\right)\right|+\alpha\left(t_{k+1}-t_{k}\right)\left|n f_{E}^{\prime}\left(t_{k+1}\right)-\sum_{i=1}^{n} \bar{f}_{i}^{\prime}\left(t_{k+1}\right)\right| \\
& \quad \leq \varepsilon+S \frac{1}{n \sqrt{n}} .
\end{aligned}
$$

We have to prove the following:

$$
f_{E}^{\prime}\left(t_{k+1}\right)=\lim _{n \rightarrow \infty} \frac{1}{n} \sum_{i=1}^{n} \bar{f}_{i}^{\prime}\left(t_{k+1}\right) .
$$

This statement has been proved by the help of the Monte-Carlo method $\left[{ }^{4,13}\right]$.

It is possible to prove that the other end point of the segment $t_{k}$ acts in an analogous way. In this case we need to change the constant $\alpha$ to $1-\alpha$. 
Thus Theorem 3, when the constant $\alpha$ is replaced with $(1-\alpha)$, is proved. It means that the constructed series of functions $\left\{\bar{f}_{n}(t)\right\}_{n=1}^{\infty}$ converges to the desired approximated consumption function $f_{R}(t), t \in[a, b]$.

\section{RESULTS}

An algorithm, in which iteration software is used that transforms the modelled consumption to the FNN-created consumption forecast, was experimented in ENav. Software obtained accepted results within 300 iterations.

To speed up the convergence of the algorithm we used the following logic:

1) select a date for which to perform a FNN forecast curve approximation;

2) construct the model function;

3) deduce a FNN forecasted curve using Eq. (6);

4) shift all the extraordinary consumption values to the minimum and maximum values;

5) correct the constructed curve in segments of monotone areas (it is known that the consumption curve has monotone areas, e.g., from hours 1 to 4 the curve is descending, from 4 to 8 it is ascending, etc.), and if the constructed curve does not fit into the stated logic, it should be corrected;

6) if the constructed curve does not fit the model function, apply the approximation algorithm to the constructed curve using second derivatives of the functions and taking into account the condition

$$
\left|f_{R}^{\prime \prime}(t)-f_{E}^{\prime \prime}(t)\right|=\min _{f \in\left\{\max _{t \in[a, b]}\left|f(t)-f_{F}(t)\right|\right\}<\varepsilon}\left|f^{\prime}(t)-f_{E}^{\prime}(t)\right| ;
$$

7) shift all extraordinary values to their minimum and maximum values;

8) approximate the FNN forecast and the model function using Eq. (6).

In the described algorithm we call the step 3 in an iterative way for 100 times, step 6 for 10 times, and step 8 for 50 times. This gives us better software performance and the same quality of result as described in the first algorithm.

\section{CONCLUSIONS}

This paper offers a solution to the problem of short-term forecast of highvoltage power consumption using feed-forward neural networks. Firstly, the rules how to create a model function were presented. Secondly, an algorithm how to adduct the FNN forecasted consumption to the model function was created. At the same time, the needed accuracy of the forecast has to be guaranteed. The created algorithm will speed up the work of the FNN used for forecasting power comsumption. The algorithm may be used to approximate forecasted data with a specified accuracy. The created algorithm has been proved mathematically. 
The described algorithm is used at Eesti Energia AS application "Event Navigator", an integrated software for technical management of transmission networks.

\section{REFERENCES}

1. Kangilaski, T. On technical management of large power transmission networks. Proc. Estonian Acad. Sci. Eng., 2002, 8, 18-37.

2. Kangilaski, T. Feed-forward neural networks for smooth operation of high voltage power transmission network. Proc. Estonian Acad. Sci. Eng., 2002, 8, 223-247.

3. Masters, T. Practical Neural Network Recipes in C++. Academic Press, San Diego, Ca, 1993.

4. Haykin, S. Neural Networks: A Comprehensive Foundation. IEEE Computer Society Press, Macmillan, New York, 1994.

5. Akhiezer, N. I. Theory of Approximation. Dover, New York, 1992.

6. Golden, R. M. Mathematical Methods for Neural Network Analysis and Design. MIT Press, Cambridge, Mass, 1996.

7. Werbos, J. P. The Roots of Backpropagation. John Wiley, New York, 1994.

8. Powell, M. J. D. Approximation Theory and Methods. Cambridge University Press, New York, 1981.

9. Schumaker, L. Spline Functions: Basic Theory. John Wiley, New York, 1981.

10. Rudin, U. Osnovy matematicheskogo analiza. Mir, Moscow, 1976 (in Russian).

11. Pugh, C. C. Real Mathematical Analysis. Springer, New York, 2002.

12. Rudin, W. Real and Complex Analysis. McGraw-Hill, New York, 1986.

13. Ermakov, C. M. Metod Monte-Karlo i Smezhnye Voprosy. Nauka, Moscow, 1971 (in Russian).

\section{Lühiajalise elektrienergia tarbimise prognoosi korrigeerimine}

\section{Taivo Kangilaski ja Vladimir Jaanimägi}

Artiklis on vaadeldud närvivõrkude poolt genereeritud elektrienergia lühiajalise tarbimise prognoosi korrigeerimist tarbimise etalonkõvera abil. Kirjeldatakse kasutatud algoritmi ning tuuakse selle matemaatiline tõestus. Loodud algoritmi võib vaadelda kui abivahendit närvivõrkude töö kiirendamiseks. Kirjeldatud algoritm on kasutusel Eesti Energia AS-is. 